2012-08-31

\title{
Response Surface Methodology Guided Release of Two Acetate Volatiles From an Oil-in-Water Emulsion
}

\author{
Mark Traynor \\ Technological University Dublin, mark.traynor@tudublin.ie \\ Roisin Burke \\ Technological University Dublin, roisin.burke@tudublin.ie \\ N. Brunton \\ Teagasc Food Research Centre
}

See next page for additional authors

Follow this and additional works at: https://arrow.tudublin.ie/tfschafart

Part of the Food Science Commons

\section{Recommended Citation}

M. Traynor, R. Burke, N. Brunton \& C. Barry-Ryan (2012) Response Surface Methodology Guided Release of Two Acetate Volatiles From an Oil-in-Water Emulsion, Journal of Culinary Science \& Technology, 10:3, 223-238, DOI: 10.1080/15428052.2012.706137

This Article is brought to you for free and open access by the School of Culinary Arts and Food Technology at ARROW@TU Dublin. It has been accepted for inclusion in Articles by an authorized administrator of ARROW@TU Dublin. For more information, please contact arrow.admin@tudublin.ie, aisling.coyne@tudublin.ie, gerard.connolly@tudublin.ie.

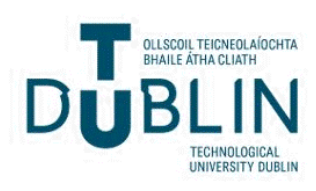




\section{Authors}

Mark Traynor, Roisin Burke, N. Brunton, and Catherine Barry-Ryan

This article is available at ARROW@TU Dublin: https://arrow.tudublin.ie/tfschafart/179 


\section{R esponse Surface M ethodology G uided R elease of T wo Acetate V olatiles from an 0 il in}

\section{Water E mulsion}

M. TRAYNOR ${ }^{\mathrm{a}}$, R. BURKE ${ }^{\mathrm{a}}, \mathrm{N} . \mathrm{BRUNTON}^{\mathrm{b}}$ and C. BARRY-RYAN ${ }^{\mathrm{c}}$

${ }^{a}$ School of Culinary Arts and Food Technology, Dublin Institute of Technology, Cathal Brugha Street, Dublin 1, Ireland

${ }^{\mathrm{b}}$ Teagasc Food Research Centre, Ashtown, Dublin 15, Ireland

${ }^{c}$ School of Food Science and Environmental Health, Dublin Institute of Technology Cathal Brugha Street, Dublin 1, Ireland

Corresponding Author

Mark Traynor

Dublin Institute of Technology,

Cathal Brugha Street,

Dublin 1,

Ireland.

$01-4024373$

mark.traynor@dit.ie 
The optimisation of the volatile release of two commonly used flavour compounds (Isoamyl acetate and Furfuryl acetate) from a food emulsion model system was evaluated using Response Surface Methodology (RSM). 27 random order settings were established using a Central Composite Faced Centered experimental design (CCF). The main and combined effects of four independent variables; concentration of Isoamyl acetate (50-90 ppm), Furfuryl acetate $(20-30 \mathrm{ppm})$, salt $(\mathrm{NaCl})(0.1-2 \%)$ and $\mathrm{pH}(5-7)$ on the responses were examined. The main objective of the present study was to determine the optimal concentration level of the four variables leading to optimal release of the volatile compounds. Quantitative measurements were conducted using solid-phase microextraction (SPME) coupled with gas chromatography mass spectrometry (GC-MS). Salt concentration and Isoamyl acetate concentration were found to have significant positive effects ( $p$ 0.001) on the release of Isoamyl acetate. The optimisation procedure indicated that the optimal conditions leading to the desirable volatile release was Isoamyl acetate 90 ppm, Furfuryl acetate 30 ppm, salt $2 \%$ w/v and $\mathrm{pH}$ 6.0176. The findings of this study can enable chefs and food manufacturers to optimise conditions for maximum flavour release from food emulsion products.

KEYWORDS Solid-phase microextraction, gas chromatography, Isoamyl acetate; Furfuryl 


\section{INTRODUCTION}

In recent times, chefs, culinary experts and food processors have become interested in the intelligent design of foods with optimal flavour characteristics (Roberts \& Taylor, 2000). Flavour is considered as one of the most important attributes determining the acceptance of food by consumers (Clarke, 1998). Therefore, information on the effect of the characteristics of food matrices with respect to flavour volatile release is vital. The production of foods/dishes in a kitchen or in a food manufacturing plant involves manipulation of the many physiochemical characteristics of the product which can influence the release of volatile molecules during gustation. For example, many foods contain significant levels of added sodium chloride $(\mathrm{NaCl})$ both to deliver flavour and act as a preservative (Mitchell et al., 2011). Sodium chloride concentrations will have a significant influence on the ionic strength of a food which will in turn influence the solubility of flavour compounds depending on their hydrophobicity (Rabe et al., 2003a). In fact, the practice of "salting out" is a well known technique for increasing headspace concentrations of hydrophobic volatile molecules prior to separation and quantification by headspace gas chromatography (Guichard, 2002; Flores et al., 2007; Pérez-Juan et al., 2007).

The $\mathrm{pH}$ of a food matrix can have a strong influence on the ionic state of volatile aroma compounds contained therein and therefore influence their concentration during gustation 
Most foods are highly complex systems, however, many can be characterised as emulsions, i.e. dispersed systems of oil and aqueous phases (McClements, 2005). Emulsions are an important class of food colloids and a wide range of products can be classed as emulsions or consist of emulsions such as salad dressings, ice cream, cream liqueurs or soft drinks (Schramm, 2005; Guzey \& McClements, 2006). The solubility of flavour compounds in the phases of the emulsions has a determinantal role in the behaviour of the flavours in the matrix and will have an over-riding influence on their sensory perception (Landy et al., 1998).

Flavour compounds are often added to the formulations of complex foods to impart characteristic flavours. For example, Isoamyl acetate is one of the most employed flavour compounds in foods $(74,000 \mathrm{~kg}$ per annum) because of its characteristic banana flavour (Yilmaztekin et al., 2008). Also, Furfuryl acetate is another flavour compound frequently used in foods as a flavourant (Burdock, 2010). Even in a simple model food system a vast array of factors can influence volatile flavour release therefore many studies employ the use of response surface methodology to reduce the number of experiments required to optimise extraction conditions (Mirhosseini \& Tan, 2009; Cheong et al., 2011; Ribeiro et al., 2011).

In the present study, response surface methodology (RSM) was used to (1) model and optimise the conditions ( $\mathrm{pH} 5-7$ and salt concentration $(\mathrm{NaCl}) 0.01 \%-2 \%$ ) leading to maximum flavour release, and (2) to study the main and interactive effects on banana volatile 
Isoamyl acetate and Furfuryl acetate were purchased from Sigma Aldrich (Dublin, Ireland). Sunflower oil (Basso Fedele and Figli, Avellino, Italy) and soy lecithin (Kelkin, Dublin, Ireland) were purchased in a local supermarket. Xanthan gum was kindly donated by Chemcolloids Ltd. (Cheshire, UK). Citric acid and hydrogen sodium carbonate, SPME fibre, $20 \mathrm{~mL}$ glass vial and Teflon coated rubber septa and aluminium screw caps were purchased from Sigma Aldrich (Dublin, Ireland.)

\section{Preparation of Emulsions}

The surfactant solutions were prepared by dispersing the soy lecithin and xanthan gum in distilled water and mixing for 1.5 hours at $60{ }^{\circ} \mathrm{C}$ using a magnetic stirring bar and magnetic stirrer hotplate (Stuart CB162, Bibby-scientific, Staffordshire, UK). The lipid phase was then heated to $60{ }^{\circ} \mathrm{C}$ and the flavour compounds were then added. The lipid phase was then slowly added to the aqueous phase while stirring. This pre-emulsion was allowed to mix for a further 5 minutes before being homogenised with a high shear blender (Silverson L4R, Silverson Machines Ltd., Chesham, UK) for 3 minutes at 8,000 rpm. $\mathrm{NaCl}$ was added to the emulsion and was allowed to dissolve under gentle stirring for 1-2 min. The $\mathrm{pH}$ was adjusted using the $0.1 \mathrm{M}$ citric acid and $0.5 \mathrm{M}$ sodium hydrogen carbonate, the $\mathrm{pH}$ was monitored using a pH meter (Thermo scientific, Orion 2 Star, Essex, UK). 
$\mathrm{mL}$ aliquots of the emulsion into a $20 \mathrm{~mL}$ headspace glass vial (O.D $2.25 \mathrm{~mm} \times \mathrm{H} 75 \mathrm{~mm}$ ) which was sealed with a stainless steel magnetic screw cap fitted with a Polytetrafluoroethylene (PTFE)/silicone septum (septum thickness $1.3 \mathrm{~mm}$ ). A PTFE coated micro stirring bar (1/2 in. $x$ 3/8 in.) was used to simulate shear stress in the mouth. A shear rate of approximately $150 \mathrm{~s}^{-1}$ was achieved by stirring at $450 \mathrm{rpm}$ (Rabe et al., 2003b). Vials were placed in a water bath set at $40{ }^{\circ} \mathrm{C}$ and allowed to equilibrate for $5 \mathrm{~min}$. A SPME fibre coated with $65 \mu \mathrm{m}$ Polydimethylsiloxane-Divinylbenzene (PDMS/DVB) was manually inserted into the headspace of the vials for adsorption. Subsequently the SPME fibre was removed from the headspace and desorbed at $250{ }^{\circ} \mathrm{C}$ in the $\mathrm{GC}$ injection port for $3 \mathrm{~min}$. The fibre was cleaned after every two extractions to ensure no carry-over between samples by soaking it in acetone for at least 15 minutes and then rinsing with $40 \%$ ethanol before reuse (Lay-Keow, 1998).

\section{GC Conditions}

Analysis of the volatile compounds absorbed on the fibre was carried out using a Varian 3800 GC coupled to a Varian Saturn 2000 ion trap mass spectrometer (Varian Chromatography Systems, Walnut Creek, CA, USA). Separation of the volatiles was accomplished on a ZB-wax column (ZB-5MS- $15 \mathrm{~m}$ x $0.25 \mathrm{~mm}$ i.d., $0.25 \mu \mathrm{m}$ film, Torrance, CA, USA). Helium, at a flow rate of $1 \mathrm{~mL} / \mathrm{min}$ was used as the carrier gas. Thermal 
were recorded after electron impact ionization under EI auto mode. Peak areas were analysed and quantified using the Varian star chromatography workstation software (v 5.0; Varian Chromatography Systems). All results were expressed as the mean values of three independent trials.

Isoamyl acetate and Furfuryl acetate were initially identified using a Varian 450-GC equipped with a Varian 320-Ms triple quadrupole (Varian Chromatography Systems, Walnut Creek, CA, USA) and CombiPal Autosampler (CTC Analytics). Compounds were also identified by use of authenticated standards and by matching mass spectra with the data stored in the NIST library of standard compounds. The data reported was the mean of 3 extraction replicates for each individual peak in the total ion chromatogram (TIC). Compounds were quantified by reference to external calibration curves constructed using the same authenticated standards and expressed as parts per million. The standard curve had an $\mathrm{R}^{2}$ value of 0.996 and 0.976 for the Isoamyl acetate and Furfuryl acetate respectively.

\section{Experimental Design}

In this study, a RSM approach was employed to (1) study the main effect and combined effect of these independent variables on response variables, (2) create empirical models between the variables and (3) optimise the physiochemical conditions for maximum volatile release in terms of the response variables studied. The effect of four independent variables 
The volatile release of each flavour compound was expressed by the peak area recorded by using GCMS. The concentration of each volatile in the headspace above the emulsion was considered as response variables in the present study. This was calculated by comparing the response for both the volatiles to that of a standard calibration curve. Table 1 illustrates the independent variables, dependent variables and the experimental design factor setting for the CCF design including the values corresponding to the levels of factors and treatments, assuming four factors, each with low, medium and high settings.

\section{Statistical Analysis}

The effects of the independent variables on the volatile flavour release of Isoamyl acetate $\left(\mathrm{Y}_{1}\right)$ and Furfuryl acetate $\left(\mathrm{Y}_{2}\right)$ from an oil in water emulsion and their interaction were analyzed using polynomial regression analysis and analysis of variance (ANOVA). A second order polynomial equation for dependent variables was established to fit the experimental data. The proposed generalised second order polynomial equation is given as

$$
\begin{aligned}
& Y_{i}=\hat{a}_{0}+\hat{a}_{1} x_{1}+\hat{a}_{2} x_{2}+\hat{a}_{3} x_{3}+\hat{a}_{4} x_{4}+\hat{a}_{11} x_{1}^{2}+\hat{a}_{22} x_{2}^{2}+\hat{a}_{33} x_{3}^{2}+\hat{a}_{44} x_{4}^{2}+\hat{a}_{12} x_{1} x_{2}+\hat{a}_{13} x_{1} x_{3}+ \\
& \hat{a}_{14} x_{1} x_{4}+\hat{a}_{23} x_{2} x_{3}+\hat{a}_{24} x_{2} x_{4}+\hat{a}_{34} x_{3} x_{4}
\end{aligned}
$$

Where $\mathrm{Y}_{1}$ is the predicted response, $\mathrm{x}_{1}, \mathrm{x}_{2}, \mathrm{x}_{3}$ and $\mathrm{x}_{4}$ are the independent linear variables, $\mathrm{x}_{1}^{2}, \mathrm{x}_{2}^{2}, \mathrm{x}_{3}^{2}$ and $\mathrm{x}_{4}{ }^{2}$ are the independent quadratic variables and $\mathrm{x}_{1} \mathrm{x}_{2}, \mathrm{x}_{2} \mathrm{x}_{3}, \mathrm{x}_{2} \mathrm{x}_{3}, \mathrm{x}_{2} \mathrm{x}_{4}$ and $\mathrm{x}_{3} \mathrm{x}_{4}$ are the independent interaction variables. In the model, $\hat{a}_{0}$ is the intercept term, $\hat{a}_{1}, \hat{a}_{2}, \hat{a}_{3}$ and 
and data was reported as the mean \pm standard error $(\mathrm{SE})$. To determine the significance of a model parameter, the t-student test was used. Differences were considered to be statistically significant at $\mathrm{p} 0.05$.

\section{Validation of Optimal Conditions}

The adequacy of response surface models for predicting the optimum response values was verified by conducting experiments under the recommended optimum conditions. The experimental predicted values of the responses were compared in order to check the validity of the models. 
Table 1 Central Composite Faced design: independent variables $\left(\mathrm{x}_{\mathrm{i}}\right)$ and response variables

$\left(\mathrm{Y}_{\mathrm{j}}\right)$

\begin{tabular}{|c|c|c|c|c|c|c|c|c|}
\hline \multirow[b]{2}{*}{ Run } & \multicolumn{4}{|c|}{ Independent variables } & \multicolumn{4}{|c|}{ Response $V$ ariables } \\
\hline & $\begin{array}{c}\text { Isoamyl } \\
\text { acetate } \\
(\mathrm{ppm})\left(\mathrm{x}_{1}\right)\end{array}$ & $\begin{array}{c}\text { Furfuryl } \\
\text { acetate } \\
(\mathrm{ppm})\left(\mathrm{x}_{2}\right)\end{array}$ & $\begin{array}{l}\mathrm{pH} \\
\left(\mathrm{x}_{3}\right)\end{array}$ & $\begin{array}{c}\text { Salt } \\
(\mathrm{w} / \mathrm{v} \%) \\
\left(\mathrm{x}_{4}\right)\end{array}$ & $\begin{array}{l}\text { Isoamyl acetate } \\
\quad(\mathrm{ppm})\left(\mathrm{Y}_{1}\right)\end{array}$ & $\begin{array}{c}\text { RSD } \\
\%\end{array}$ & $\begin{array}{l}\text { Furfuryl acetate } \\
\quad(\mathrm{ppm})\left(\mathrm{Y}_{2}\right)\end{array}$ & RSD \% \\
\hline 1 & 50 & 20 & 5 & 0.1 & 150.203 & 7.54 & 136.656 & 10.78 \\
\hline 2 & 90 & 20 & 5 & 0.1 & 284.492 & 4.99 & 246.29 & 6.12 \\
\hline 3 & 50 & 30 & 5 & 0.1 & 106.706 & 3.80 & 242.59 & 6.10 \\
\hline 4 & 90 & 30 & 5 & 0.1 & 96.766 & 17.96 & 81.099 & 29.95 \\
\hline 5 & 50 & 20 & 7 & 0.1 & 73.21 & 7.44 & 316.638 & 14.01 \\
\hline 6 & 90 & 20 & 7 & 0.1 & 245.249 & 7.21 & 174.6 & 9.11 \\
\hline 7 & 50 & 30 & 7 & 0.1 & 20.752 & 2.34 & 40.872 & 9.61 \\
\hline 8 & 90 & 30 & 7 & 0.1 & 92.950 & 0.86 & 77.23 & 1.45 \\
\hline 9 & 50 & 20 & 5 & 2 & 110.913 & 1.40 & 276.907 & 2.22 \\
\hline 10 & 90 & 20 & 5 & 2 & 277.857 & 4.57 & 207.025 & 5.64 \\
\hline 11 & 50 & 30 & 5 & 2 & 140.771 & 4.07 & 262.064 & 5.94 \\
\hline 12 & 90 & 30 & 5 & 2 & 269.778 & 5.97 & 281.686 & 7.40 \\
\hline 13 & 50 & 20 & 7 & 2 & 124.429 & 2.31 & 168.838 & 3.50 \\
\hline 14 & 90 & 20 & 7 & 2 & 364.551 & 3.55 & 133.485 & 4.17 \\
\hline 15 & 50 & 30 & 7 & 2 & 40.416 & 13.82 & 78.382 & 35.93 \\
\hline 16 & 90 & 30 & 7 & 2 & 309.311 & 6.52 & 253.627 & 7.88 \\
\hline 17 & 50 & 25 & 6 & 1.05 & 24.118 & 7.88 & 48.0824 & 29.00 \\
\hline 18 & 90 & 25 & 6 & 1.05 & 287.81 & 2.27 & 241.216 & 2.78 \\
\hline 19 & 70 & 20 & 6 & 1.05 & 193.997 & 21.54 & 101.409 & 28.72 \\
\hline 20 & 70 & 30 & 6 & 1.05 & 197.999 & 7.19 & 317.921 & 9.54 \\
\hline v2.21 & 70 & 25 & 5 & ettp $1 / .95 \mathrm{w} w \mathrm{~W}$ & pdf4ffete? $283 \mathrm{~m}$ & 6.77 & 192.837 & 9.80 \\
\hline 22 & 70 & 25 & 7 & 105 & 56220 & 0.10 & 54711 & 021 \\
\hline
\end{tabular}




\section{RESULTS}

Fitting the Response Surface Models and Repeatability

Regression analysis was carried out to fit mathematical models to the experimental data. The regression coefficients and analysis of variance of the coded independent variables are presented in Table 2. The resulting regression coefficients for the coded dependent variables showed that the regression model for Isoamyl acetate $\left(\mathrm{Y}_{1}\right)$ had a statistically good fit. The $\mathrm{R}^{2}$ statistic indicated that the response surface model accounted for $90 \%$ of variation in the Isoamyl acetate response $\left(\mathrm{Y}_{1}\right)$, which is above the minimum recommended $\mathrm{R}^{2}$ value $(0.80)$ (Joglekar \& May, 1987). For the Furfuryl acetate response $\left(\mathrm{Y}_{2}\right)$, only $44 \%$ of the variation could be explained by the response surface model, therefore having a statistically poor fit and poor prediction capabilities. Significant (p 0.001) regression P-value and a non-significant (p 0.05) lack of fit P-value indicated that the mathematical model fitted well to the experimental data for Isoamyl acetate $\left(\mathrm{Y}_{1}\right)$ (Bezerra et al., 2008). Although the lack of fit Pvalue was non-significant ( $\mathrm{p}$ 0.05) for Furfuryl acetate response $\left(\mathrm{Y}_{2}\right)$, the regression $\mathrm{P}$-value was also non-significant ( $\mathrm{p}$ 0.05), thus the mathematical model might require slight improvements.

The repeatability was determined to check the precision of the method. The repeatability of the experimental procedure was evaluated by calculating the relative standard deviation percentage (RSD \%) of three replicates for each experimental condition (Table 1). The 
Table 2 Regression coefficients and analysis of variance of coded dependent variables

\begin{tabular}{ccc}
\hline Regression coefficients & I soamyl acetate $\left(\mathbf{Y}_{\mathbf{1}}\right)$ & Furfuryl acetate $\left(\mathbf{Y}_{\mathbf{2}}\right)$ \\
\hline$\left.\beta_{0}\right)$ & $154.777^{* * *}$ & 156.99 \\
$\beta_{1}$ & $79.8471^{* * *}$ & 6.95713 \\
$\beta_{2}$ & $-30.5251^{*}$ & -7.0209 \\
$\beta_{3}$ & -14.1489 & -34.9317 \\
$\beta_{4}$ & $36.3422^{* * *}$ & 27.0138 \\
$\beta_{1}{ }^{2}$ & 14.1938 & -3.93245 \\
$\beta_{2}{ }^{2}$ & 54.2279 & 61.0833 \\
$\beta_{3}{ }^{2}$ & -41.519 & -24.8076 \\
$\beta_{4}{ }^{2}$ & -14.0331 & -4.26023 \\
$\beta_{12}$ & -15.8271 & 12.9608 \\
$\beta_{13}$ & 20.8096 & 8.5205 \\
$\beta_{14}$ & $27.2739^{*}$ & 15.448 \\
$\beta_{23}$ & -8.41039 & -21.5007 \\
$\beta_{24}$ & 19.9065 & 32.6185 \\
$\beta_{34}$ & 15.3371 & -18.5034 \\
\hline $\mathbf{R}^{2}$ & 0.902 & 0.437 \\
\hline Regression (P-value) & $0.00^{* * *}$ & 0.768 \\
\hline Lack of fit (P-value) & 0.251 & 0.36 \\
\hline ( & & \\
\hline
\end{tabular}

$\beta_{\mathrm{i}}$ : estimated regression for the main linear effects.

$\beta_{i}{ }_{i}^{j}$; the estimated regression coefficients for the quadratic effects.

$\beta_{\mathrm{ii}}$; the estimated regression coefficients for the interaction effects.

* Significant (p 0.05), ** Significant (p 0.01), *** Significant (p 0.001)

PDF Creator - PDF4Free v2.0 Effect of Independent Variables qntth. 
importance of the different regression coefficients, and provides a visual indication of whether a variable has a positive or negative influence on the response.

Figure 1 Main effects and significant parameters on the recovery of Isoamyl acetate from emulsion headspace

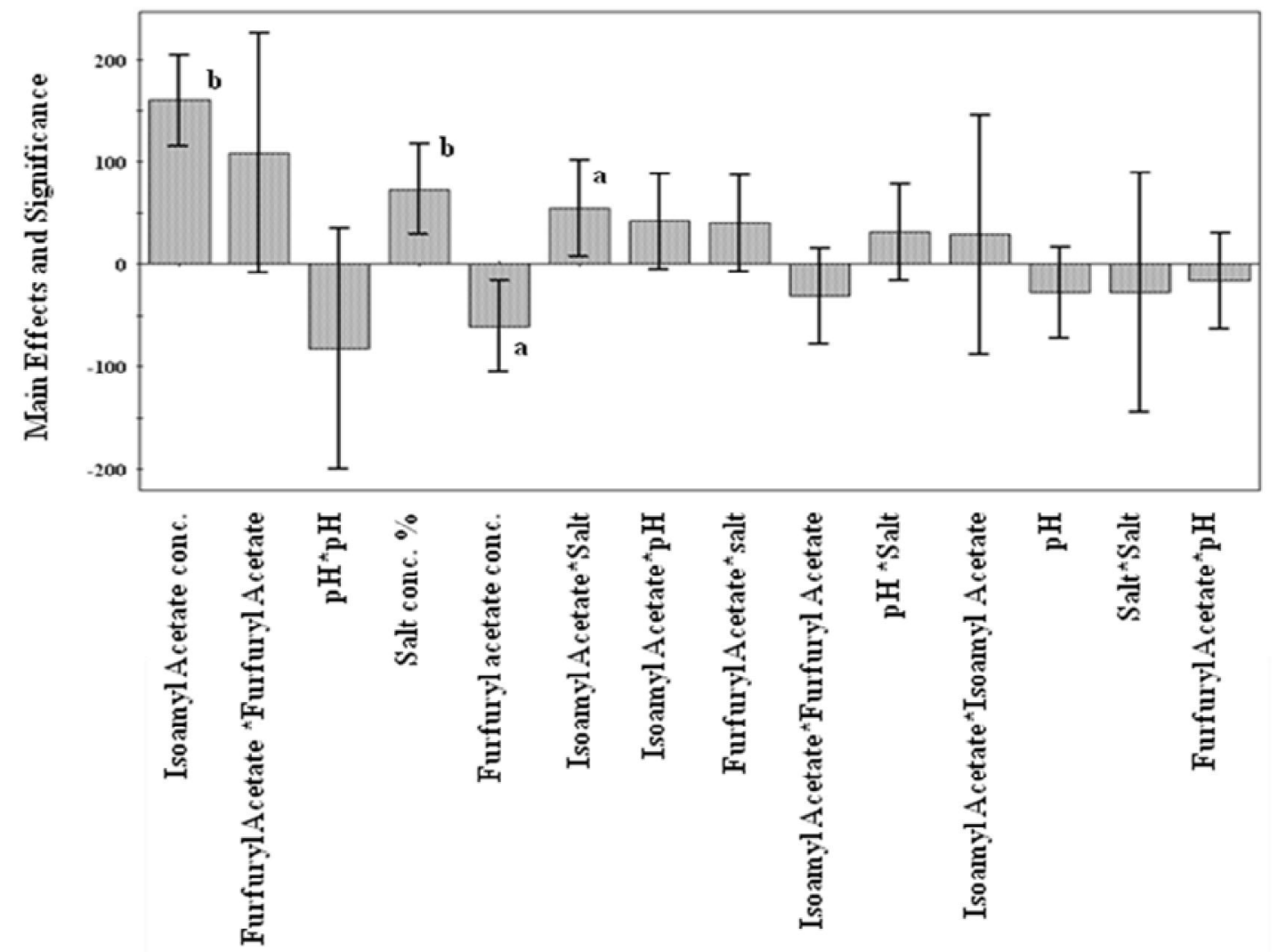

${ }^{\mathbf{a}}$ Significant (p 0.05), ${ }^{\mathbf{b}}$ Significant (p 0.001) 
Isoamyl acetate concentration and salt concentration $\left(\mathrm{x}_{14}\right)$ on the Isoamyl acetate response $\left(\mathrm{Y}_{1}\right)$. With regards to the effect of Isoamyl acetate concentration on the release of Furfuryl acetate $\left(\mathrm{Y}_{2}\right)$ from the emulsion, no significant ( $\mathrm{p}$ 0.05) effects were found.

The regression results demonstrate that Furfuryl acetate concentration $\left(\mathrm{x}_{2}\right)$ had a significant effect ( $\mathrm{p}$ 0.05) on the Isoamyl acetate response $\left(\mathrm{Y}_{1}\right)$. Moreover, this effect of Furfuryl acetate on the release of Isoamyl acetate in to the headspace of the emulsion proved to be a negative effect. No significant ( $p$ 0.05) effects were found for Furfuryl acetate concentration on the release of Furfuryl acetate $\left(\mathrm{Y}_{2}\right)$ from the emulsion. In addition, the $\mathrm{pH}$ $\left(\mathrm{x}_{3}\right)$ proved to have no significant influence (p 0.05) on Isoamyl acetate $\left(\mathrm{Y}_{1}\right)$ or Furfuryl acetate (Y2) release from the emulsion. Salt concentration $\left(\mathrm{x}_{4}\right)$, had a significantly ( 0.001$)$ positive effect on the volatile release of Isoamyl acetate $\left(\mathrm{Y}_{1}\right)$ (Figure 3).

\section{Validation of Optimal Conditions}

The optimal conditions for the targeted responses were generated by the Modde 5.0 software (Table 3). At optimal conditions (Isoamyl acetate $90 \mathrm{ppm}\left(\mathrm{x}_{1}\right)$, Furfuryl acetate 30 ppm $\left(\mathrm{x}_{2}\right)$, salt $2 \% \mathrm{w} / \mathrm{v}\left(\mathrm{x}_{3}\right)$ and $\left.\mathrm{pH} 6.018\left(\mathrm{x}_{4}\right)\right)$, the predicted values were $326.41 \mathrm{ppm}$ and 811.34 ppm for Isoamyl acetate $\left(\mathrm{Y}_{1}\right)$ and Furfuryl acetate $\left(\mathrm{Y}_{2}\right)$ release from the emulsion respectively. HS-SPME GCMS analysis was carried out at the optimal conditions to verify the model. At optimal conditions, the product contained Isoamyl acetate (273.75 ppm) ( $\left.\mathrm{Y}_{1}\right)$ 


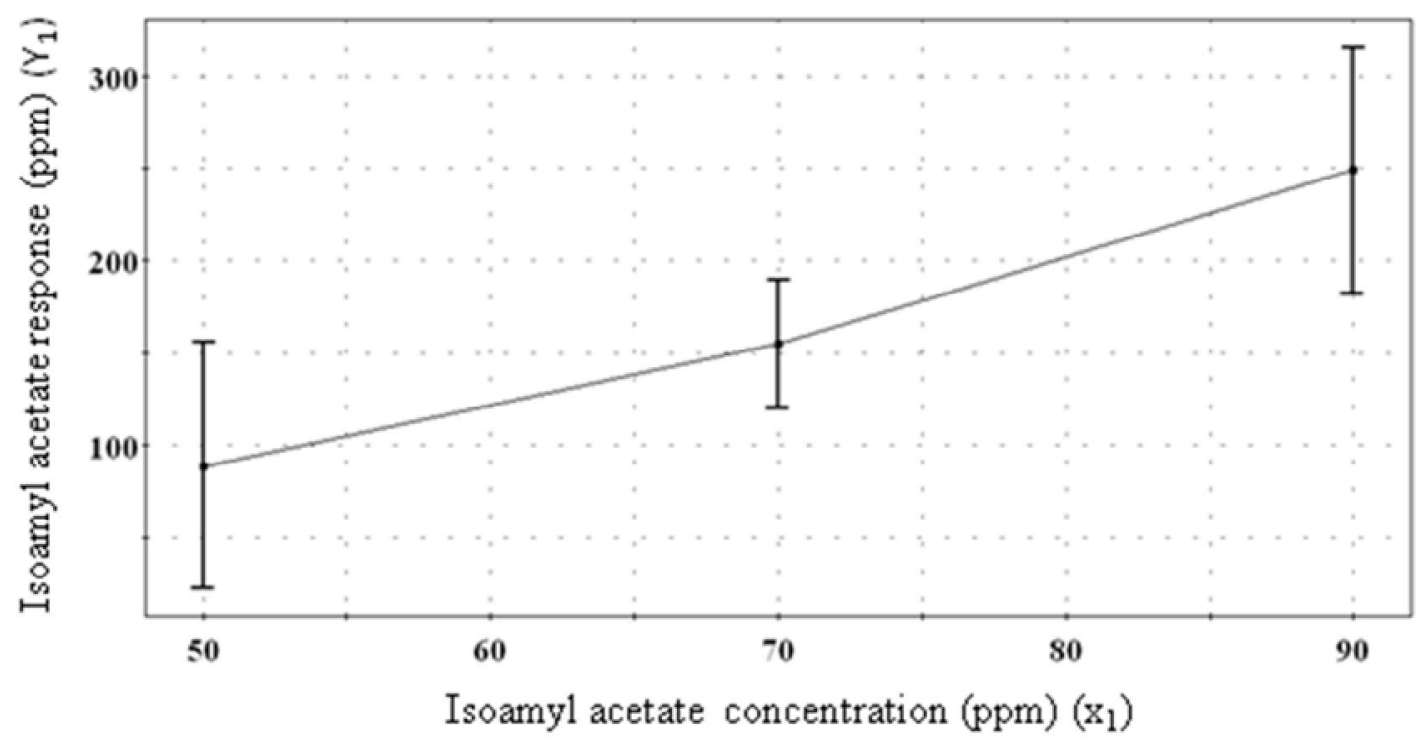

Figure 3 Response surface plot for effect of salt concentration \% on Isoamyl acetate response

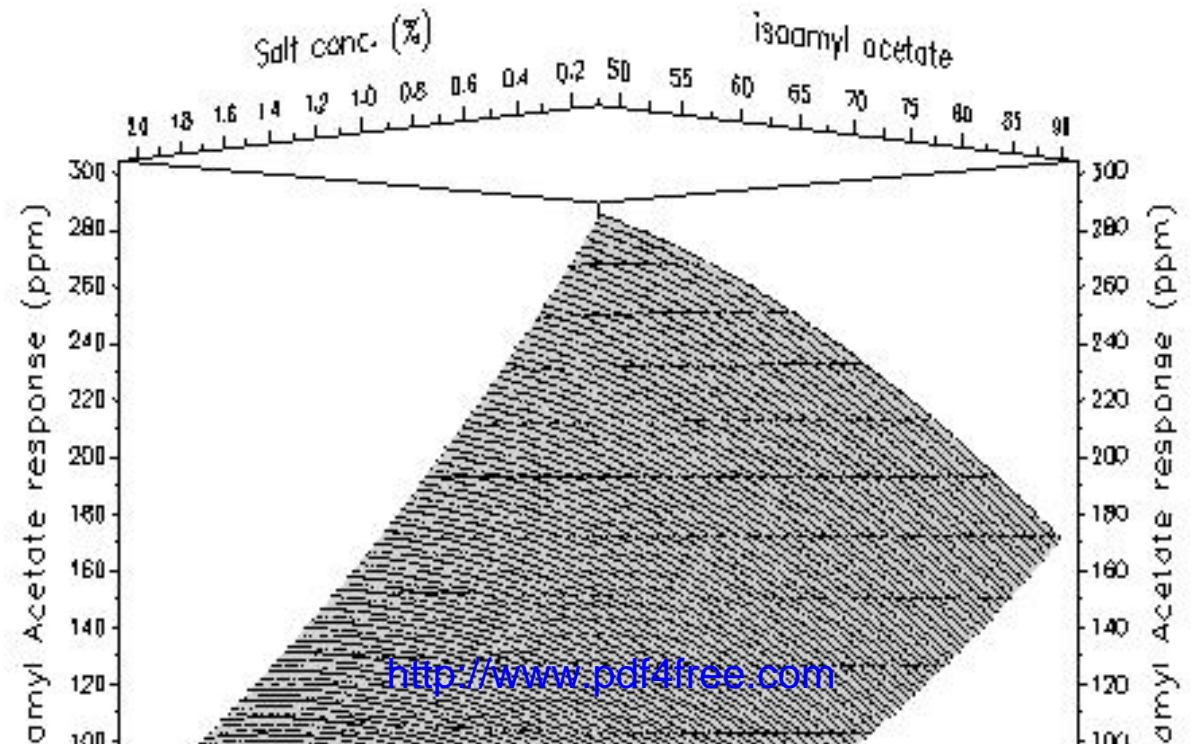


Table 3 List of predicted optimal conditions generated by Modde 5.0 RSM software

\begin{tabular}{cccccc}
\hline $\begin{array}{c}\text { Isoamyl } \\
\text { acetate } \\
(\mathrm{ppm})\left(\mathrm{x}_{1}\right)\end{array}$ & $\begin{array}{c}\text { Furfuryl } \\
\text { acetate } \\
(\mathrm{ppm})\left(\mathrm{x}_{2}\right)\end{array}$ & $\begin{array}{c}\mathrm{pH} \\
\left(\mathrm{x}_{3}\right)\end{array}$ & $\begin{array}{c}\text { Salt } \\
(\mathrm{w} / \mathrm{v} \%) \\
\left(\mathrm{x}_{4}\right)\end{array}$ & $\begin{array}{c}\text { Isoamyl acetate } \\
\text { response }(\mathrm{ppm})\left(\mathrm{Y}_{1}\right)\end{array}$ & $\begin{array}{c}\text { Furfuryl acetate response } \\
(\mathrm{ppm})\left(\mathrm{Y}_{2}\right)\end{array}$ \\
\hline 88.7161 & 20 & 5.564 & 2 & 348.817 & 619.021 \\
89.8708 & 20 & 5.530 & 2 & 354.724 & 618.816 \\
90 & 30 & 6.253 & 2 & 326.96 & 764.177 \\
$* 90$ & $\mathbf{3 0}$ & $\mathbf{6 . 0 1 7}$ & $\mathbf{2}$ & $\mathbf{3 2 6 . 4 0 9}$ & $\mathbf{8 1 1 . 3 4 4}$ \\
89.1528 & 20 & 5.540 & 2 & 350.355 & 619.016 \\
89.4616 & 20 & 5.532 & 2 & 351.955 & 618.942 \\
88.7752 & 20 & 5.558 & 2 & 348.871 & 619.04 \\
90 & 30 & 6.163 & 2 & 327.295 & 783.01 \\
\hline
\end{tabular}

*optimal condition selected by Modde 5.0 software from the list of generated optimal conditions

\section{DISCUSSION}

Justification of concentration ranges was based on the Flavour and Extract Manufacturers Association (FEMA) reported uses in literature (Burdock, 2010) and from preliminary sensory analysis, where differences in minimum and maximum concentrations of Furfuryl acetate were successfully identified by a panel (data not shown). Besides showing the optimal conditions for Isoamyl acetate recovery, the mathematical model identified and described significant effects of the independent variables and some interesting interactions between the variables on the Isoamyl acetate response. These interactions are substantial and a 'one

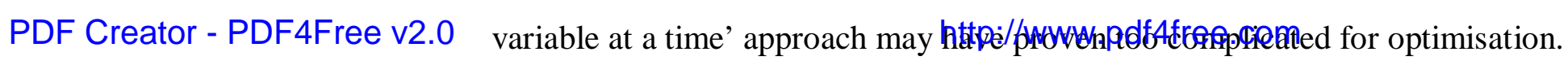


concentration range of the Furfuryl acetate (20-30 ppm) being quite narrow in comparison to Isoamyl acetate (50-90 ppm). Additionally, the contour plots for Furfuryl acetate release (Figure 4) shows a 'saddle point', which is a stationary point of neither a maximum nor minimum response (Myers et al., 2009). This indicates that the optimum conditions for Furfuryl acetate release from the emulsion lie outside the experimental range investigated in this study.

Figure 4 Contour plot of Furfuryl acetate release from emulsion as a function of Furfuryl acetate concentration and $\mathrm{pH}$

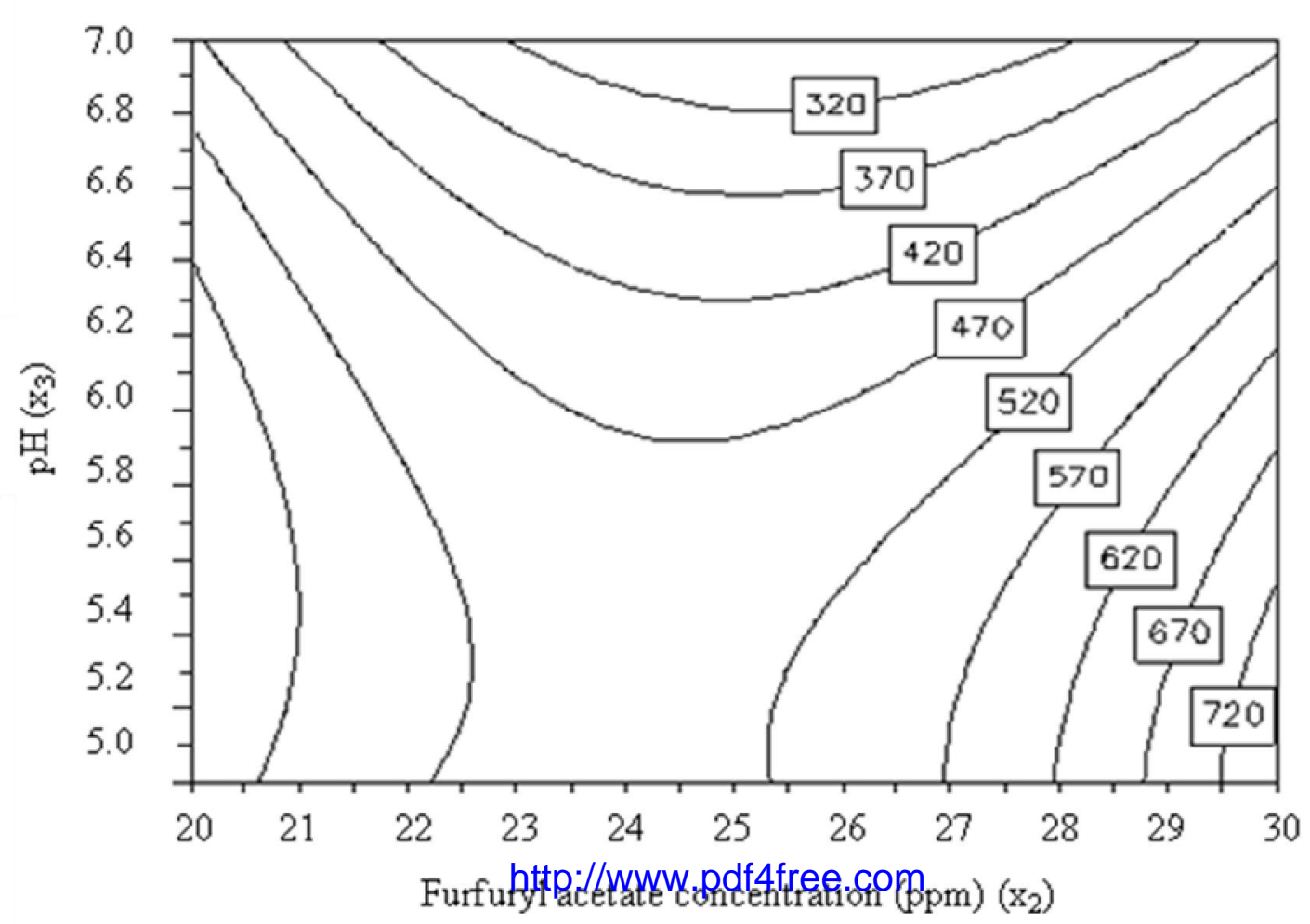


effect that Furfuryl acetate concentration had on the Isoamyl acetate volatile response could be a result of competition between the volatiles for space on the SPME fibre. It was found in previous studies (Matich et al., 1996; Murray, 2001; Howard et al., 2005), that volatile compounds exhibited competition for extractions sites on the SPME fibres. Higher molecular weight compounds can have the tendency to displace those with lower molecular weights, thereby causing inaccuracies in the relative amounts of analytes present, especially with fibres coated with PDMS. This may explain why an increase in concentration of the higher molecular weight compound Furfuryl acetate resulted in a decrease in the lower molecular weight compound Isoamyl acetate being absorbed onto the SPME fibre.

Furthermore, the possible competition for space on the fibre between the volatiles may have resulted in a "knock on" effect on the other variables, thus masking any additional significant effects on the responses. A possible solution to this may involve reducing the concentrations of both volatiles to a level that will result in competition for space on the fibre between the volatiles. However, the use of a concentration range below 20 ppm for Furfuryl acetate may have provided little useful information with regard to sensory properties of the emulsion.

Similarly, the lack of a significant effect ( $\mathrm{p} 0.05$ ) of $\mathrm{pH}$ on the responses may be due to the narrow range of $\mathrm{pH}$ selected. This experimental range was selected to fit in with the context of the work being undertaken. Food products such as cream sauces and dressings 
The perception of flavour and aroma volatiles in foods is influenced by the solubility of volatile compounds, which subsequently can be affected by the level of salt present in a food (Mitchell et al., 2011). Salts are often added to aqueous samples to increase the concentrations of the aroma compounds in the vapour phase (Guichard, 2002). The addition of salt to foodstuffs results in the decreased availability of water molecules for the solubilisation of flavour compounds, thus, an increase in flavour release from the food product into its headspace, consequently an increase in perceived flavour concentration during consumption (Rabe et al., 2003a; Flores etal., 2007).

From an analytical point of view, dissolution of salt into the sample matrix is a simple way to enhance the partition coefficient into the headspace of the volatile compounds due to the 'salting out' effect in headspace analysis (Steffen \& Pawliszyn, 1996). According to the results, salt concentration had a pronounced effect on the release of Isoamyl acetate from the emulsion. An increase in salt led to an increase in overall extraction yield of Isoamyl acetate from the emulsion (Figure 3). It would be expected that the addition of salt to the emulsion, increased the ionic strength of the solution, which subsequently decreased the solubility of the hydrophobic compounds in the aqueous phase, thereby increasing the partition coefficient of the volatile compounds (Rocha et al., 2001).

Similar observations were also reported in previous studies (Mirhosseini et al., 2007; Cheong et al., 2010; Cheong et al., 2011), where extraction efficiency increased with addition

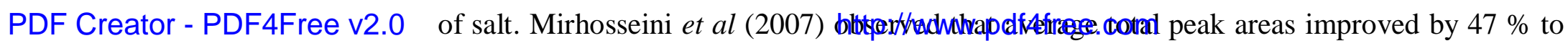


effect salt on the extraction efficiency of volatiles from a matrix from a purely technical point of view, with a goal for extracting volatiles qualitatively, hence, much higher levels of salt were investigated $(0-30 \% \mathrm{w} / \mathrm{v})$. In the present study, the model system was based around common food emulsions, such as cream sauces and dressing, therefore, human consumption was considered, and so salt content in the relatively narrow range of $0.1-2 \%$ was investigated. The use of concentration above this level would have made the emulsion unacceptable from a sensory and product development point of view.

Modifying food flavour is a long standing practice, chefs, culinarians and food manufacturers aim to produce food products that are flavoursome and that maximise the enjoyment provided through the sensory experience for consumers. The way in which flavour components modify the perceived flavour of food has advanced from a stage of simply awareness of the situation, to an understanding of the interactions involved at a qualitative and quantitative level (Taylor \& Hort, 2007). From a practical point of view, optimising the release from the food matrix of two flavour compounds that are strongly associated with positive fruity notes in foods can be a method of enhancing flavour perception. The perception of aroma and flavour is dependent up on the concentration and odour threshold of the volatile compounds present in the food (Guichard, 2002). Thus, finding the optimum concentration of volatile compounds for maximum flavour release is a crucial step in the development of flavoursome food emulsions, which are an important class of food colloids. 
when creating food emulsions such as cream sauces and dressings etc. The main effects of

Isoamyl acetate concentration and salt concentration should be considered as critical factors when studying the release of Isoamyl acetate from an oil in water emulsion.

\section{References}

Bezerra, M., Santelli, R., Oliveira, E., Villar, L. \& Escaleira, L. (2008). Response surface methodology (RSM) as a tool for optimization in analytical chemistry. Talanta 76(5): 965977.

Burdock, G. A. (2010). Fenaroli's handbook of flavor ingredients. Boca Raton, CRC Press.

Cheong, K., Tan, C., Mirhosseini, H., Chin, S., Che Man, Y., Hamid, N., Osman, A. \& Basri, M. (2011). Optimization of equilibrium headspace analysis of volatile flavor compounds of malaysian soursop (Annona muricata): Comprehensive two-dimensional gas chromatography time-of-flight mass spectrometry (GC×GC-TOFMS). Food Chemistry 125(4): 1481-1489.

Cheong, K., Tan, C., Mirhosseini, H., Hamid, N., Osman, A. \& Basri, M. (2010). Equilibrium headspace analysis of volatile flavor compounds extracted from soursop (Annona muricata) using solid-phase microextraction. Food Research International 43(5): 1267-1276.

Clarke, J. (1998). Taste and flavour: their importance in food choice and acceptance. Proceedings of the Nutrition Society 57: 639-643.

Flores, M., Gianelli, M. P., Pérez-Juan, M. \& Toldrá, F. (2007). Headspace concentration of selected dry-cured aroma compounds in model systems as affected by curing agents. Food Cheristry 102(2): 488-493.

Guichard, E. (2002). Interactions between flavour compounds and food ingredients and their influence on flavour perception. Food Reviews International 18: 4970.

Guzey, D. \& McClements, J. (2006). Formation, stability and properties of multilayer emulsions for application in the food industry. Advances in Colloid and Interface Science 
Lay-Keow, N. (1998). Analysis of vodkas and white rums by SPME-GC-MS Applications of solid phase microextraction Pawliszyn, J. Cambridge, UK, The Royal Society of Chemistry: 393-406.

Lee, J., Ye, L., Landen, W. O. \& Eitenmiller, R. R. (2000). Optimization of an extraction procedure for the quantification of vitamin $\mathrm{E}$ in tomato and broccoli using response surface 13-methodology. J ournal of Food Composition and Analysis 13: 45-57.

Matich, A., Rowan, D. \& N., B. (1996). Solid Phase Microextraction for quantitative headspace sampling of apple volatiles. Analytical Chemistry 68: 4114-4118.

McClements, D. J. (2005). Emulsions: Principles, Practice and Techniques. Boca Raton, CRC Press.

Mirhosseini, H., Salmah, Y., Nazimah, S. A. H. \& Tan, C. P. (2007). Solid-Phase Microextraction for headspace analysis of key volatile compounds in orange beverage emulsion. Food Cheristry 105(4): 1659-1670.

Mirhosseini, H., Tan, C., Hamid, N. \& Yusof, S. (2008). Effect of Arabic gum, Xanthan gum and orange oil on flavour release from diluted orange beverage emulsion. Food Chemistry 107: 1161-1172.

Mirhosseini, H. \& Tan, C. P. (2009). Response Surface Methodology and multivariate analysis of equilibrium headspace concentration of orange beverage emulsion as function of emulsion composition and structure. Food Cherristry 115(1): 324-333.

Mitchell, M., Brunton, N. P. \& Wilkinson, M. G. (2011). Impact of salt reduction on the instrumental and sensory flavor profile of vegetable soup. Food Research International 44(4): 1036-1043.

Murray, R. (2001). Limitations to the use of Solid-Phase Microextraction for quantitation of mixtures of volatile organic sulfur compounds. Analytical Chemistry 73: 1646-1649.

Myers, R. H., Montgomery, D. C. \& Anderson-Cook, C. M. (2009). Response Surface Methodology: process and product optimization using designed experiments New Jersey, Wiley and Sons.

Pérez-Juan, M., Flores, M. \& Toldrá, F. (2007). Effect of ionic strength of different salts on the binding of volatile compounds to porcine soluble protein extracts in model systems. Food

Research International 40(6): 687tf93. $/$ /www.pdf4free.com

Rahe $S$ Krinos $U$ \& Beroer $R$ (2003a) Initial dvnamic flavour release from sodium 
and principal component analysis. Chemometrics and Intelligent Laboratory Systems 102(1): 45-52.

Roberts, D. \& Taylor, A. (2000). Flavour Release New Orleans, United States, American Chemical Society.

Rocha, S., Ramalheira, V., Barros, A. n., Delgadillo, I. \& Coimbra, M. A. (2001). Headspace Solid Phase Microextraction (SPME) analysis of flavor compounds in wines. Effect of the matrix volatile composition in the relative response factors in a wine model. Journal of Agricultural and Food Chemistry 49: 5142-5151.

Schramm, L. (2005). Emulsions, Foams, and Suspensions: Fundamentals and Applications. Weinheim, Wiley-VCH.

Smith, J. (2010). Evaluation of Analytical Data, Food Analysis, Nielsen, S. New York Springer: 55-67.

Steffen, A. \& Pawliszyn, J. (1996). Analysis of flavor volatiles using Headspace Solid phase Microextraction. J ournal of Agricultural and Food Chemistry(44): 2187-2193.

Taylor, A. \& Hort, J. (2007). Modifying Flavour: an introduction, Modifying Flavour in Food, Taylor, A. and Hort, J. Cambridge, Woodhead Publishing Limited.

Yilmaztekin, M., Erten, H. \& Cabaroglu, T. (2008). Production of Isoamyl Acetate from sugar beet molasses by Williopsis saturnus var. saturnus. J ournal of the Institute of Breving 114(1): 34-38. 